\title{
Children's optimal interpretations of indefinite subjects and objects
}

\author{
Helen de Hoop and Irene Krämer
}

Radboud University Nijmegen

\begin{abstract}
We find a general, language-independent pattern in child language acquisition in which there is a clear difference between subject and object noun phrases. On the one hand, indefinite objects tend to be interpreted non-referentially, independently of word order and across experiments and languages. On the other hand, indefinite subjects tend to be interpreted referentially in most contexts, even in contexts where adults would favour a non-referential reading. In this article we offer an explanation for this pattern within the framework of bidirectional Optimality Theory. This explanation will focus on clarifying in what sense children's interpretations deviate from the adult interpretations, and clarifying the nature of the linguistic knowledge that the 4-year old child will need to acquire in order to become a competent, adult-like speaker and hearer of her language.
\end{abstract}

\section{A subject-object asymmetry in interpretation}

Consider the following sentence (Lidz and Musolino 2002):

(1) Donald didn't find two guys.

In principle, the sentence in (1) can have two readings depending on whether the object is interpreted within the scope of the negation or outside the scope of the negation. Hence, the readings may be paraphrased as 'It is not the case that Donald found two guys' and 'There are two guys that Donald didn't find', respectively. It can also be argued that the difference in interpretation lies in the interpretation of the object two guys. In the 'wide scope' reading, the object denotes referentially, whereas in the 'narrow scope' reading the object denotes nonreferentially. 
We are aware of the fact that different authors have labeled the two readings differently, depending on their different analyses of how the two interpretations come about, but in this paper we will stick to the labels referential and non-referential to refer to the relevant readings of indefinite objects. The difference between the referential and non-referential readings is evident also in sentence pairs that lack scope interactions, as is illustrated below. The two readings differ in the anaphoric element they may combine with. On the one hand, when the object a guy is interpreted non-referentially, it may be followed by the indefinite anaphor one in (2). On the other hand, when the indefinite object is interpreted referentially, it may be followed by the referential pronoun him in (3).

(2) Donald saw a guy, and Ronald saw one too. [non-referential]

(3) Donald saw a guy, and Ronald saw him too. [referential]

In the remainder of this article we are mainly concerned with indefinite noun phrases. In accordance with many proposals in the literature, we assume that the referential reading corresponds to type $e$ in extensional type theory, while the non-referential reading of an indefinite is assumed to correspond to type $<e, t>$, i.e. the predicative type (Partee 1987; Van Geenhoven 1996; van der Does and de Hoop 1998)

Lidz and Musolino (2002) tested children's as well as adults' interpretations of sentences like (1) above. While they found that adult speakers of English can easily get both readings, the (4-year-old) children have a strong preference for the non-referential object reading. They found similar results for Kannada, a Dravidian language.

\begin{tabular}{|c|c|c|}
\hline naanu & eraDu pustaka & ood-al-illa. \\
\hline $\mathrm{I}_{\mathrm{NOM}}$ & book & read-INF-NEG \\
\hline
\end{tabular}

As pointed out by Lidz and Musolino (2002), a sentence like (4) is ambiguous between a referential and a non-referential object reading in Kannada too, as witnessed by the fact that adult speakers of Kannada easily get both readings. Moreover, Lidz and Musolino (2002) found the same pattern for children as observed for English, namely that the children have a strong preference for the non-referential reading of the object noun phrase.

The above observations are in accordance with the pattern found for Dutch (Krämer 2000). 
(5) Je mag twee keer een potje omdraaien.

you may two time a pot around-turn

"You may turn a pot around twice."

(6) Je mag een potje twee keer omdraaien.

you may a pot two time around-turn

"You may turn a pot around twice."

In Dutch, the indefinite object noun phrase can either occur to the right of the adverbial phrase twee keer 'twice' as in (5), or it can occur to the left of it, as in (6). The left position in (6) is usually referred to as the scrambled position, the right position in (5) as the unscrambled position. Krämer (2000) tested the interpretation of scrambled and unscrambled indefinite objects in children between $4 ; 0$ and $8 ; 0$. Children as well as adults get a non-referential reading for the unscrambled indefinite. For most children below age 7, however, the scrambled indefinites are also interpreted non-referentially, whereas adults always interpret the scrambled indefinites referentially.

To sum up, for all of the above sentences, it was found that children between roughly 4 and 6 years old prefer to interpret the object noun phrases non-referentially, even in situations when adults interpret them referentially. As the examples show, the children's preference for non-referential direct objects is not determined by word order, as the object follows the adverbial element in English, whereas it precedes it in Kannada and Dutch, nor can it be determined by a structural relation such as c-command (contra Lidz and Musolino 2002) as the referential object is assumed to be c-commanded by the adverbial phrase in English and Kannada, but crucially it is not in Dutch.

One straightforward explanation for these findings could be that children have a general preference to interpret indefinite noun phrases non-referentially. As a consequence, the indefiniteness of the noun phrase would lead to a non-referential reading, independent of its position in the sentence. However, this cannot be the right explanation, as for indefinite subjects, the picture is completely different. In a number of experiments, children, just like adults, provided nearly exclusively referential interpretations of indefinite subject noun phrases. Consider for example (7) (Musolino 1998).

(7) Some horses won't jump over the fence. 
Musolino (1998) found that sentence (7) was accepted by the children $100 \%$ of the time as a remark about a story in which some horses did, and some horses did not jump over the fence. In other words, all children interpreted the subject in (7) referentially. Musolino's findings were consistent with the findings of Bergsma-Klein (1996) for Dutch. She found that children correctly assign a referential ('wide scope') reading to indefinite subjects as in (8).

(8) Een meisje gleed twee keer uit.

A girl slipped two time out particle

"A girl slipped twice."

At this point, we conclude that cross-linguistically we find a subject-object asymmetry in children's interpretation of indefinites. When adults assign a referential interpretation to indefinite subjects, children generally do the same (Bergsma-Klein 1996; Musolino 1998; Krämer 2000). But when adults assign a referential interpretation to indefinite objects, children cross-linguistically do not do the same (Bergsma-Klein 1996; Krämer 1998; Musolino 1998; Foley, Lust et al. 2000; Krämer 2000; Su 2001; Lidz and Musolino 2002; Miller 2002).

So far, we have concentrated on the subject-object asymmetry as far as it concerns the referential interpretation of indefinite noun phrases. The asymmetry can be further extended, however, when we consider the non-referential interpretation of indefinites. As we mentioned above, when adults assign a non-referential ('narrow scope') reading to an object, so do children (de Boysson-Bardiès and Bacri 1977; Krämer 1998; Krämer 2000; Lidz and Musolino 2002). For example, $100 \%$ of the children between $4 ; 0$ and $6 ; 10$ years old correctly interpret the indefinite object in (9) non-referentially (Krämer 2000).

(9) Het meisje heeft geen appel geplukt. the girl has no apple picked “The girl didn’t pick an apple."

A final piece of evidence for the subject-object asymmetry concerns the non-referential reading of indefinite subjects. Termeer (2002) recently found that when adults assign a nonreferential interpretation to a subject, children prefer a referential interpretation. That is, only 
$32 \%$ of the children between age 8;7 and 10;4 get an adult-like non-referential ('narrow scope') reading for the embedded indefinite subject in (10) (Termeer 2002).

$\begin{array}{lllllll}\text { Er ging twee keer een jongen van de glijbaan af. } \\ \text { there went two time a boy of the slide } & \text { off } \\ \text { "Twice, there went a boy down the slide." } & & & \end{array}$

In conclusion, children are adult-like in their interpretation of referential indefinite subjects and in their interpretation of non-referential indefinite objects. They differ from adults when they have to interpret non-referential indefinite subjects and when they have to interpret referential indefinite objects. How can we explain this pattern? Note that cross-linguistically subjects outrank objects in referentiality. It is a well-known typological generalization, supported by statistical evidence, that subjects tend to be referential, definite, topical, animate, high-prominent in the discourse, among other notions, while objects tend to be non-referential, indefinite, inanimate, low-prominent in the discourse, instead (a.o. Comrie 1989; Aissen 2003; Lee 2003). Children seem to behave in accordance with that generalization, that is, they assign a referential interpretation to subjects and a non-referential interpretation to objects. Adults, however, can depart from this pattern when required. More precisely, they are able to assign a non-referential reading to indefinite subjects, and a referential reading to indefinite objects. Children's non-adultlike interpretations of the example sentences above can be characterized as a failure to depart from the general pattern. Why do children fail in this respect? In section 2 we will analyze the adult pattern in terms of markedness and we will provide an Optimality Theoretic account of this pattern in section 3. Our account can also straightforwardly explain why children deviate from the adult pattern in exactly the way they do.

\section{Form and meaning of indefinites and the principle of markedness}

In this section we will discuss the markedness principle (a.o. Horn 1984) with respect to subject and object position and meaning. The markedness principle states that marked forms are used for marked meanings. As a consequence, if both marked and unmarked forms are available, unmarked forms tend to be used for unmarked meanings. 
Let us start with the position and meaning of objects in Dutch. We have seen above that indefinite objects can occur either to the right of an adverb (the unscrambled position) or to its left (the scrambled position). This is illustrated in the sentences (11) and (12) below:

$\begin{array}{llllll}\text {... dat ik net een } & \text { zwarte kat } & \text { zag. } \\ \text {... that I } \text { th just a } & \text { black cat } & \text { saw } \\ \text { "... that I just saw a black cat." } & & & \end{array}$

$\begin{array}{lllll}\text {... dat ik een } & \text { zwarte kat } & \text { net } & \text { zag. } \\ \text {... that I } \text { a } & \text { black cat } & \text { just } & \text { saw } \\ \text { "...that I just saw a black cat." } & & & \end{array}$

The preferred reading of the unscrambled indefinite object in (11) is the non-referential reading which is indeed the unmarked (i.e., most frequent) meaning for indefinite objects. In contrast, the scrambled indefinite object in (12) receives a referential ('specific') reading. The unmarked (most frequent) position for indefinite objects is the unscrambled position. When an indefinite object ends up in the marked (scrambled) position, this gives rise to a shift in meaning. In (12), the indefinite object gets a referential reading, which may indeed be considered a marked (less frequent) meaning of an indefinite object. Note that other 'marked' meanings happen to exist as well, such as 'generic', or 'contrastively focussed' readings, dependent on the nature of the noun phrase, the adverb and the context (cf. a.o. de Hoop 1996). In other words, the relation between form and meaning of scrambled and unscrambled indefinite objects is in accordance with the markedness principle.

The scrambled position is not the marked (less frequent) position for all objects. Pronouns usually scramble, so for pronouns the word order in (14) is the unmarked one.

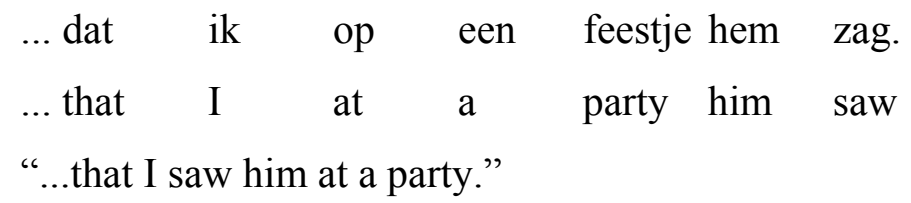

... dat ik hem op een feestje zag.
... that I him at a party saw
"...that I saw him at a party."


The unmarked reading that goes with the unmarked (scrambled) position of the pronominal object in (14) is the anaphoric reading. When the pronoun occupies the marked (unscrambled) position, this induces a shift in meaning. The reading that arises for the pronoun in the unscrambled position in (13) is a deictic (i.e. non-anaphoric) reading, which is indeed a marked (less frequent) meaning for pronouns. It is naturally obtained when the speaker stresses the pronoun, preferably accompanied by a movement of the head towards a male individual or by pointing her finger at him.

To sum up, we see that scrambling in Dutch obeys the principle of markedness, i.e., marked forms are used for marked meanings. For pronominal objects, this means that the unscrambled position is used for the deictic interpretation, while for indefinite objects, this means that the scrambled position is used for the referential interpretation.

Let us now turn to indefinite subjects. Indefinite subjects can occur either in standard (sentence-initial) subject position, or in the embedded position in a there-sentence. The two positions can be associated with two different readings (Milsark 1977).

Een konijn kwam uit de hoed.

a rabbit came out the hat

"A rabbit came out of the hat."

(16) $\mathrm{Er}$ kwam een konijn uit de hoed. there came a rabbit out the hat "There came a rabbit out of the hat."

There is a difference between Dutch and English (cf. De Hoop 1996), but at least what the two languages have in common is that the preferred reading for the indefinite subject in (15) is the referential reading (the rabbit plays an active role in the discourse), whereas the preferred reading for the indefinite subject in (16) is the non-referential (purely existential) reading.

As to form, example (15) presents what we consider the unmarked case: the subject appears in standard subject position. As a consequence of the assumption that the standard subject position is the unmarked position for subjects, we take the embedded position in the existential sentence to be a marked (less frequent) position for subjects. As to the meaning of indefinite subjects, we observe a conflict in interpretation. On the one hand, subjects tend to get a referential interpretation (they outrank objects in terms of prominence or referentiality), 
in accordance with the subject-object asymmetry of interpretation. On the other hand, indefinites tend to get a non-referential interpretation (as the term 'indefinite' already suggests, indefinites favour an indefinite, i.e. non-specific, non-referential reading). Thus, unlike in the case of indefinite objects, the two conditions are in conflict. We assume that the first condition is the strongest one, such that the referential reading is the unmarked reading for indefinite subjects. In accordance with the markedness principle, the unmarked, referential, reading is then associated with the unmarked form (the standard subject position). The marked meaning for indefinite subjects is the non-referential reading which arises when the subject is encountered in the marked (embedded) subject position.

In conclusion, the subject-object asymmetry in connection with the markedness principle adequately describes the adult pattern of the interpretation of indefinite noun phrases in relation to their position in the sentence. On the one hand, the unmarked reading for an indefinite object noun phrase is the non-referential reading (triggered both by the indefiniteness of the noun phrase and the fact that it is the object). On the other hand, the unmarked reading for an indefinite subject is the referential reading (in accordance with the subject-object asymmetry, but thereby violating the indefiniteness condition). Furthermore, the unmarked position for an indefinite object is the unscrambled position, and the unmarked position for an indefinite subject is the standard subject position. Hence, the markedness principle correctly derives the fact that adults link the scrambled position to the referential reading of indefinite objects and the embedded subject position to the non-referential reading of indefinite subjects. In the next section, we will offer an Optimality Theoretic analysis of this adult pattern that can then be used to explain why and in what sense exactly children deviate from this pattern.

\section{An Optimality Theoretic analysis of the subject-object asymmetry}

In this section we will develop an Optimality Theoretic account of the optimal interpretations of indefinite subjects and objects. We will not only explain why the optimal interpretation of an indefinite object is usually the non-referential reading (the unmarked case), but also elaborate upon the derivation of the marked, referential, reading for an indefinite object in a certain context. We will do the same for the unmarked, referential, and the marked, nonreferential readings of indefinite subject. 
Subsequently, we will show how we may link markedness of form to markedness of meaning using a bidirectional Optimality Theoretic approach, following Blutner (2000). The markedness principle is widely attested across the languages of the world (cf. a.o. Horn 1984). Recall that the markedness principle states that marked forms are used for marked meanings (and unmarked forms for unmarked meanings). Blutner (2000) has proven the markedness principle to result from (weak) bidirectional Optimality Theory. But before we apply Blutner's (2000) framework of bidirectional Optimality Theory to the data in the previous sections, we will provide some background information to the idea of optimization of interpretation.

Optimality Theory (Prince and Smolensky 1993; 1997) applied to the domains of syntax and semantics involves two closely related issues: 1. given a semantic input within a certain context, what is its optimal expression; and 2. given a syntactic input within a certain context, what is its optimal interpretation? In Optimality Theoretic syntax (henceforth, OT syntax), the input is usually considered to be a semantic structure (e.g., a predicate-argument structure) which gives rise to an, in principle infinite number of syntactic structures of which the most harmonic or optimal one is eventually realized as the grammatical structure that syntactically expresses the semantic input. Thus, OT syntax optimizes syntactic structure with respect to a semantic input. One might say that OT syntax takes the perspective of a speaker, who has a certain thought and wants to express it correctly and optimally in a syntactic structure.

OT semantics, on the other hand, takes the point of view of a hearer, who hears (or reads) an utterance with a certain syntactic structure and wants to interpret this structure correctly and optimally. In OT semantics, the input is associated with an, in principle infinite number of possible interpretations of which the most harmonic or optimal one is eventually arrived at as the correct interpretation of the input utterance (Hendriks and de Hoop 2001).

The constraints that play a role in the optimization process can be syntactic, phonological, pragmatic or semantic in nature. Part of the set of constraints is assumed to be universal and some constraints may play a role in both semantics and syntax. Obviously, then, the crucial difference between OT syntax and OT semantics does not lie in the (type of) constraints under consideration, but in the direction of optimization. In OT syntax, the direction of optimization is from meaning to form, whereas in OT semantics, it is from form to meaning.

Since Optimality Theory does not support a modular view on grammar, linguistic phenomena and linguistic processes can be the result of the interaction among different 
linguistic components. Because Optimality Theory allows for a formalization of multidimensional constraint interaction, it seems particularly suited to deal with the complex interaction among constraints on form, intonation, context and interpretation.

Let us now turn to the analysis of the possible forms and interpretations of indefinite subjects and objects. The constraints we use are not new; they have been linguistically motivated in the literature, although we may formulate them slighthly differently. What is new is our conception of these constraints as soft, i.e., violable. In order to determine the optimal output for a certain input, one must try to satisfy as many constraints as possible, and only violate constraints when this allows one to satisfy the stronger ones.

We will use the following constraints on meaning and form in our analysis:

(17) M1: Subjects outrank objects in referentiality, i.e., subjects get a referential interpretation, while objects get a non-referential interpretation.

(18) M2: Indefinite noun phrases get a non-referential interpretation.

(19) F1: Indefinite objects do not scramble.

(20) F2: Subjects are in standard subject position, referred to as [Spec,IP].

These four constraints will give us the unmarked meanings of indefinite subjects and objects as the optimal candidates from an OT-semantic point of view, and the unmarked forms from an OT-syntactic point of view. These constraints, however, cannot account for the marked meanings (and neither for the marked forms).

However, marked meanings of indefinite subjects and objects do occur. Adult speakers of English can easily interpret an indefinite object such as the one in (1) above, both non-referentially (the unmarked reading) and referentially (the marked reading). Similarly, indefinite subjects such as the one in (7) above, receive either an unmarked, referential, or a marked, non-referential, reading in English. Both with respect to indefinite objects as with respect to indefinite subjects, the marked reading can be the optimal reading of the unmarked form (sometimes, the unmarked form is the only available form) within a certain context. For example, if sentence (1) above is embedded in a story in which the two guys that Donald didn't find have already been brought into the attention of the hearer, then the referential reading will come out as optimal. Likewise, if the sentence in (7) is uttered out of the blue and some is unstressed (written as sm by Milsark 1977), then the optimal reading for the indefinite subject is the non-referential reading. So, without additional information from the (linguistic or extra-linguistic) context or from the intonational pattern, the unmarked reading is the 
optimal one, but a marked reading can be the optimal one within a certain context. In Optimality Theory this can be explained if we allow pragmatic and prosodic constraints to interfere with the meaning constraints formulated above. For example, different factors may favour a referential reading: anaphoric noun phrases are interpreted referentially, animate noun phrases are easier to interpret referentially than inanimate ones, agentivity favours a referential reading as well as topic-hood and (high-) prominency in the discourse.

In general, we assume that contextual and/or prosodic information can trigger marked meanings of unmarked forms. In some cases, the unmarked form is the only form available. This holds for instance for the indefinite direct objects in English. But as for the indefinite subjects in English and Dutch and the indefinite objects in Dutch, there is an alternative, 'marked' form available. Yet, even in those cases, the unmarked form can still receive a marked interpretation within a certain context. That is, the indefinite subject in standard subject position can get a non-referential reading in a presentational context (Milsark 1977). Similarly, an unsrambled indefinite object can receive a referential reading within a certain context, as already pointed out by De Hoop (1996).

Crucially, however, when a marked form is used, the marked reading emerges irrespective of the context. That is, adult hearers of Dutch interpret a scrambled indefinite object referentially, even in the absence of any further contextual or prosodic information. Similarly, an indefinite subject is interpreted non-referentially when it is in the embedded position of an existential construction. In conclusion, in the absence of further context, marked forms give rise to marked meanings, just like unmarked forms give rise to unmarked meanings. Bidirectional OT (Blutner 2001) provides us with a straightforward explanation of how these unmarked and marked form-meaning pairs arise.

The basic idea of bidirectional OT is to simultaneously optimize in both directions, from form to meaning and from meaning to form. That is, bidirectional OT adds to the general procedure of optimization that the hearer takes into account the speaker's perspective (and, the other way around, the speaker takes into account the hearer's perspective). That is, if a form is associated with a certain interpretation within a certain context by a hearer, then within that same context, the same meaning would have been expressed by the same form if the hearer would have been the speaker. To put it differently, the composition of a formmeaning pair within a context goes hand in hand with the decomposition of that formmeaning pair within that same context. Crucially, bidirectional optimization involves the evaluation of form-meaning pairs against a set of ranked (cross-modular) constraints. 
Instead of giving the relevant definitions of how to determine which pairs of forms and meanings are optimal, we will just provide a schematic example in order to illustrate the basic characteristics of bidirectional OT. Assume that we have two forms $f_{1}$ and $f_{2}$ and two meanings $m_{1}$ and $m_{2}$. We stipulate that the form $f_{l}$ is less marked (more harmonic) than the form $f_{2}$ which means that for a given meaning, form $f_{1}$ will be the optimal form. Furthermore, interpretation $m_{1}$ is less marked (more harmonic) than the interpretation $m_{2}$, which means that for a given form, meaning $m_{l}$ will be the optimal meaning. Thus, the following ordering relation between form-meaning pairs can be derived, represented in an arrow diagram, where the arrows point to the preferred pair.

$$
\begin{array}{ccc}
<\mathrm{f}_{1}, \mathrm{~m}_{1}> & < & <\mathrm{f}_{2}, \mathrm{~m}_{1}> \\
\uparrow & \uparrow \\
& & \\
<\mathrm{f}_{1}, \mathrm{~m}_{2}> & \leftarrow & <\mathrm{f}_{2}, \mathrm{~m}_{2}>
\end{array}
$$

In Blutner's (2000) framework a form-meaning pair $<f, m>$ is called super-optimal if and only if there is no other super-optimal pair $\left\langle f^{\prime}, m>\right.$ such that $<f^{\prime}, m>$ is more harmonic than $<f, m>$ and there is no other super-optimal pair $\left\langle f, m^{\prime}>\right.$ such that $\left\langle f, m^{\prime}>\right.$ is more harmonic than $\langle f, m>$. The reader may verify that according to this definition, there are two superoptimal pairs in the diagram in (21), namely $<f_{1}, m_{1}>$ and $<f_{2}, m_{2}>$. Indeed, although $f_{2}$ is not an optimal form itself and $m_{2}$ is not an optimal meaning, the pair $\left\langle f_{2}, m_{2}>\right.$ is super-optimal, because there is no super-optimal pair that blocks it (that is, the two candidates $\left\langle f_{1}, m_{2}\right\rangle$ and $<f_{2}, m_{1}>$ are not super-optimal, because they are both blocked by the other super-optimal pair $\left.<f_{1}, m_{1}>\right)$.

Thus, bidirectional OT provides us with two super-optimal form-meaning pairs, in accordance with the markedness principle: the unmarked form with the unmarked meaning, and the marked form with the marked meaning.

Let us now give a bidirectional OT analysis of the data under discussion in this paper. We evaluate form-meaning pairs against the constraints M1, M2, F1, and F2 given above (see (17)-(20)). The super-optimal pairs are indicated with the symbol $\sin$ the tableaux. 


\begin{tabular}{|c|c|c|c|}
\hline $\begin{array}{l}\text { Input: }[\mathrm{f}, \mathrm{m}] \text { indefinite object } \\
\text { f: } 1 \text {. unscrambled; } 2 \text {. scrambled } \\
\text { m: } 1 \text {. non-referential (type }<e, t>\text { ); 2. referential (type } e \text { ) }\end{array}$ & M1 & M2 & F1 \\
\hline$[-$ scrambling, $<\mathrm{e}, \mathrm{t}>]$ & $\checkmark$ & $\checkmark$ & $\checkmark$ \\
\hline [- scrambling, e] & $*$ & $*$ & $\checkmark$ \\
\hline$[+$ scrambling, $<\mathrm{e}, \mathrm{t}>]$ & $\checkmark$ & $\checkmark$ & $*$ \\
\hline [+ scrambling, e] & $*$ & $*$ & $*$ \\
\hline
\end{tabular}

In the above tableau we see that although the indefinite object that combines a referential meaning with a scrambled word order, violates all three constraints that seem to be relevant, it does represent a super-optimal pair, simply because there is no super-optimal pair available that has either a more harmonic form or a more harmonic meaning. The only other superoptimal pair has both a more harmonic form and a more harmonic meaning and therefore it cannot block the 'marked' super-optimal pair. Thus, the bidirectional OT approach straightforwardly accounts for the scrambling phenomenon of indefinite objects in Dutch.

A similar analysis can be provided for the possible forms and meanings of indefinite subjects, as illustrated below.

(23) Bidirectional OT tableau: indefinite subjects

\begin{tabular}{|c|c|c|c|}
\hline $\begin{array}{l}\text { Input: [f, m] indefinite subject } \\
\text { f: 1.[Spec,IP] (standard); 2. [Spec,VP] (embedded) } \\
\text { m: 1. referential (type e); 2. non-referential (type }<e, t>\text { ) }\end{array}$ & M1 & M2 & $\mathrm{F} 2$ \\
\hline$[[$ Spec, IP $]$, e $]$ & $\checkmark$ & $*$ & $\checkmark$ \\
\hline$[[$ Spec, IP $],<\mathrm{e}, \mathrm{t}>]$ & $*$ & $\checkmark$ & $\checkmark$ \\
\hline$[[\mathrm{Spec}, \mathrm{VP}], \mathrm{e}]$ & $\checkmark$ & $*$ & $*$ \\
\hline$[[$ Spec, VP $],<\mathrm{e}, \mathrm{t}>]$ & $*$ & $\checkmark$ & $*$ \\
\hline
\end{tabular}

Because the constraint M1 (subjects get a referential reading) outranks M2 (indefinites get a non-referential reading), the meaning that satisfies M1 and violates M2 is the optimal (unmarked) meaning, while the meaning that violates M1 but satisfies M2 is less harmonic 
(marked). One super-optimal pair links the unmarked meaning to the unmarked position (the standard subject position) while the other super-optimal pair links the marked meaning to the marked position (the embedded subject position).

In conclusion, we find that a bidirectional OT analysis straightforwardly explains the adult pattern of the interpretation of both indefinite objects and indefinite subjects. Adults are able to evaluate form-meaning pairs. That means that they cannot only find the optimal form for a certain meaning or the optimal meaning of a certain form, they are also capable of determining as a super-optimal pair the combination of a form that is sub-optimal from a unidirectional syntactic perspective and a meaning that is sub-optimal from a unidirectional semantic perspective.

We would now like to use the bidirectional OT framework for our explanation of the children's pattern of interpreting indefinite subjects and objects. Clearly, as soon as children have acquired the constraints M1 and M2 and their ranking, they will assign a non-referential reading to indefinite objects, and a referential reading to indefinite subjects, independent of the position these noun phrases occupy. This is exactly in accordance with what has been attested in the experiments, as discussed in section 1 above. In other words, these results indicate that children have acquired the relevant interpretive constraints and their ranking, and therefore they can determine the optimal meaning of the optimal form (that is, the 'unmarked' super-optimal pair).

But children deviate from adult's interpretations, when they are required to arrive at a 'marked' meaning. Sometimes this is due to the fact that the children do not have acquired all the relevant cross-modular constraints yet or that they have not yet captured the right weighting or ranking of these constraints. They have difficulties in integrating the information from the context and the intonational pattern into their interpretation of the form. A different explanation is available when children do not obtain a marked meaning of a marked form. In that particular case, it seems that they optimize the interpretation of the marked (e.g., scrambled) form uni-directionally instead of bidirectionally. Thus, children's optimal interpretation of a marked form will be the same as their optimal interpretation of an unmarked form in that same context. In that case, we predict a non-referential reading of the indefinite object in scrambled position and a referential reading of the indefinite subject in embedded subject position. In order to get the right interpretation for the indefinite subject or object in a marked position, however, the child must learn to apply the process of optimization bidirectionally. What is needed therefore is the following 'reasoning' by the child: I can find the optimal interpretation for this form, but I notice that the form is sub- 
optimal; the speaker would have used the optimal form for the optimal meaning (the 'unmarked' super-optimal form-meaning pair), therefore I must choose the sub-optimal meaning for this sub-optimal form, which will give me another ('marked') super-optimal form-meaning pair. We think that this bidirectional OT analysis of indefinite subject and object interpretation clarifies in what sense children's interpretations deviate from the adult interpretations. Obviously, they might also have problems in determining the optimal interpretation in a certain context independently of the markedness of the form. But they definitely fail when they have to assign a sub-optimal (marked) reading to a sub-optimal (marked) form. Before the 4-year old child will be a competent, adultlike hearer of her language, she must acquire the full process of optimization of interpretation, which not only involves taking into account cross-modular constraint interaction but also the speaker's perspective of optimization in a bidirectional appraoch.

\section{Some exceptional interpretations}

The analysis presented in the previous section straightforwardly derives the data concerning children's unmarked interpretations of indefinite subjects and objects described in section 1 . The OT account explains the similarity to the cross-linguistic adult interpretations with respect to the referential reading of indefinite subjects and the non-referential reading of indefinite objects. Furthermore, our approach accounts for the fact that children deviate exactly in those contexts when adults assign a marked meaning to a marked form, i.e., when an indefinite subject must be interpreted non-referentially because it is in an embedded position, and when an indefinite object must be interpreted referentially because it is in a scrambled position.

However, it would not be true to say that children never arrive at a marked meaning at all. In this section we will discuss two cases where children seem to get a marked meaning. In the first case they incorrectly assign a marked (non-referential) interpretation to an indefinite subject. In the second case they correctly assign a marked (referential) interpretation to an indefinite object. We claim that these cases do not provide counter-examples to our optimization approach. In fact, both cases can be explained within the uni-directional perspective of optimization of interpretation.

One case was described by Krämer (2000). She found that for sentence (24), approximately half the children had a non-referential interpretation of the indefinite subject, 
i.e. the children manipulated two different marbles, once each. Adults, however, would favour a referential reading of the indefinite subject in (24).

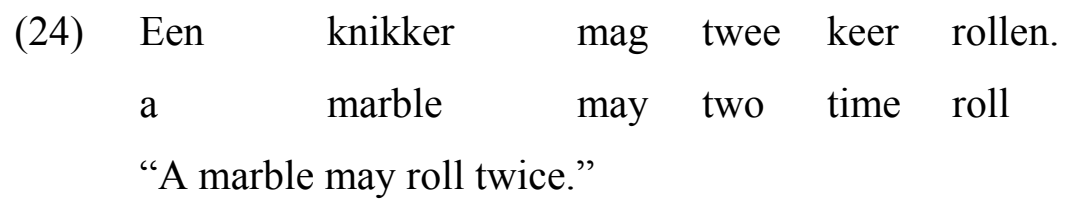

We have argued above that indefinite subjects show a conflict in interpretation. One constraint states that subjects favour a referential reading and the other constraint states that indefinites favour a non-referential reading. Therefore, unlike indefinite objects, indefinite subjects are subject to two violating constraints. This makes the interpretation of an indefinite subject dependent on the ranking of the two constraints. If the subject constraint outranks the indefiniteness constraint, we predict a referential reading, whereas if the ranking is the other way around, we predict a non-referential reading. Since in Dutch the indefinite subject in (24) must get a referential reading (hence, it takes scope over twee keer 'twice'), we conclude that the subject condition must outrank the indefiniteness condition, and therefore the referential reading is the winner. However, as we already pointed out above, there are more factors than just the form (indefinite) and the grammatical function (subject or object) that contribute to a referential or non-referential interpretation of a noun phrase. Animacy, agentivity, topicality, and/or discourse-prominence contribute to referentiality, too. Children who get a nonreferential reading for the subject in (24) do not have captured yet the relative dominance of the subject condition. The problem is that in this case the other factors together strongly suggest a non-referential reading, that is, the fact that 'a marble' is inanimate, that it cannot be an agent, that it is not very likely to play a prominent role in the discourse, and that it is lowly individualized in the sense that is almost impossible to distinguish one marble from the other. We think that this 'conspiracy' of factors pointing into the direction of a non-referential reading indeed explains why half of the children arrive at the non-referential reading as the optimal interpetation in this context. By contrast, children do correctly assign a referential reading to the indefinite subject in the intransitive sentence in (8) above (Bergsma-Klein 1996). But in that sentence, although the subject is indefinite, it refers to an individual that is clearly animate and moreover, which was already introduced in the context of a story, unlike the marble of (24).

The second case we would like to discuss is one where children are adult-like in that they obtain a marked reading of an unmarked form within a certain context. Indeed, such 
interpretations are found by Miller and Schmitt (2003). In a context in which the indefinite object is made high-prominent in the discourse, $92 \%$ of the children between age $3 ; 10$ and 5;8 indeed assign a referential reading to the indefinite object. A relevant example is given in (26) with the preceding context in (25):

(25) [Picture 1] This is Kelly and these are eggs that are all in a basket. Look, Kelly is painting them. Her mom told her to paint all of the eggs before going outside to play. Let's see what happened.

[Picture 2] Look, now Kelly is going outside to play. But what about this one? (point to leftover egg and pause) Let's see if the monster knows what happened:

(26) Kelly didn't paint an egg.

As pointed out by Miller and Schmitt (2003), children are able to interpret an egg in (26) referentially, just like adults. As in the case of subjects, we assume that apart from the indefinite form and the grammatical function, other factors may trigger either a referential or a non-referential reading. Clearly, although an egg is both indefinite and inanimate, it does seem to play an important role in the discourse, and the hearer's attention has certainly been drawn to this individual. This makes the referential reading the winning interpretation after all, not only for adults, but for most of the children as well (cf. also Gualmini 2002).

\section{Conclusion}

We have presented a optimization approach of the interpretation of indefinite subjects and objects that accounts for the subject-object asymmetry as well as the markedness principle. For children, the acquisition of unmarked meanings for unmarked forms seems relatively easy to acquire, while most deviations from the adult patterns are found when children have to assign marked meanings to unmarked or marked forms. The last pattern is presumably the most difficult to acquire since it involves the evaluation of form-meaning pairs.

\section{References}

Aissen, J. (2003). "Differential Object Marking: Iconicity vs. Economy." Natural Language and Linguistic Theory 21: 435-483. 
Bergsma-Klein, W. (1996). Specificity in child Dutch: An experimental study, Utrecht University.

Blutner, R. (2000). "Some aspects of optimality in natural language interpretation." Journal of Semantics 17: 189-216.

Comrie, B. (1989). Language Universals and Linguistic Typology. Chicago, University of Chicago Press.

de Boysson-Bardiès, B. and N. Bacri (1977). "The interpretation of negative sentences." International Journal of Psycholinguistics 4: 73-81.

de Hoop, H. (1996). Case Configuration and Noun Phrase Interpretation. New York \& London, Garland Publishing.

Foley, C., B. Lust, et al. (2000). On the Acquisition of an Indefinite Determiner: Evidence for Unselective Binding. Proceedings of the 24th Annual Boston University Conference on Language Development. S. C. Howell, S. A. Fish and T. Keith-Lucas. Somerville, Massachusetts, Cascadilla Press. 1: 286-298.

Gualmini, A. (2002). Children Do Not Lack Some Knowledge. University of Maryland Working Papers in Linguistics.

Hendriks, P. and H. de Hoop (2001). "Optimality theoretic semantics." Linguistics and Philosophy 24: 1-32.

Horn, L. (1984). Towards a new taxonomy of pragmatic inference: Q-based and R-based implicature. Meaning, form, and use in context: Linguistic applications. D. Schiffrin.

Washington, Georgetown University Press: 11-42.

Krämer, I. M. (1998). Children's Interpretations of Indefinite Object Noun Phrases. Evidence from the Scope of Negation. Linguistics in the Netherlands 1998. R. v. Bezooijen and R. Kager. Amsterdam/Philadelphia, John Benjamins Publishing Company: 163-174.

Krämer, I. M. (2000). Interpreting Indefinites. An experimental study of children's language comprehension, Utrecht University.

Lee, H. (2003). Parallel Optimization in Case Systems. Nominals: Inside and Out. M. Butt and T. King. Stanford, CSLI.

Lidz, J. and J. Musolino (2002). "Children's command of quantification." Cognition 84: 113154.

Miller, K. (2002). Scope of Spanish bare singulars in child language. Michigan.

Miller, K. and C. Schmitt (2003). Wide-scope Indefinites in English Child Language. Utrecht.

Milsark, G. (1977). "Toward an Explanation of Certain Peculiarities of the Existential Construction in English." Linguistic Analysis 3: 1-29. 
Musolino, J. (1998). Universal grammar and the acquisition of semantic knowledge: An experimental investigation into the acquisition of quantifier negation interaction in English, University of Maryland.

Partee, B. H. (1987). Noun phrase interpretation and type shifting principles. Studies in Discourse Representation Theory and the Theory of Generalized Quantifiers. J. Groenendijk, D. d. Jongh and M. Stokhof. Dordrecht, Foris.

Prince, A. and P. Smolensky (1993). Optimality theory. Rutgers Center for Cognitive Science, Technical Report RuCCSTR-2.

Prince, A. and P. Smolensky (1997). "Optimality Theory: From Neural Networks to Universal Grammar." Science 275: 1604-1610.

Su, Y.-C. (2001). Scope and Specificity in Child Language. BUCLD 25, Somerville, MA, Cascadilla Press.

Termeer, M. (2002). "Een meisje ging twee keer van de glijbaan." A study of indefinite subject NPs in child language. Utrecht.

van der Does, J. and H. de Hoop (1998). "Type-shifting and scrambled definites." Journal of Semantics 15: 393-416.

Van Geenhoven, V. (1996). Semantic Incorporation and Indefinite Descriptions. Semantic and Syntactic Aspects of Noun Incorporation in West Greenlandic, University of Tübingen. 